\title{
EI Lazarillo de Tormes: texto carnavalesco. Contra las lecturas satíricas y erasmistas
}

\author{
Jorge Ramírez Caro \\ Universidad Nacional, Costa Rica \\ Universidad de Costa Rica
}

\section{Resumen}

El estudio plantea la índole camavalesca, deliberadamente ambigua entre el burlón y el burlado, mediante el recurso de la parodia. Así, la tradición popular de la risa se sobrepone al presunto carácter moralizante, didáctico y serio que la crítica le ha atribuido al Lazarillo de Tormes. En vez del atributo picaresco, a lo largo de los episodios hay una voluntad de escenificación del escarnio público, sin ninguna intención ejemplarizante; la vida del persona je apunta al contacto directo con lo mundano, lejos del misticismo o la mera contemplación.

\section{Abstract}

This study discusses carnival literature, which — by means of parodydeliberately expresses ambiguity between the one who ridicules and the one who is ridiculed. Thus the popular tradition of laughter appears more important than the severe, didactic, moralizing intention which has been attributed to Lazarillode Tormes. Instead of picaresque features, in all of the episodes an effort is made to mock the character in public, but without any intention of acting as an example; the life of Lazarillo is real, not symbolic or contemplative. 
Todo aquello que es realmente grande debe incluir un elemento de risa. Mijaíl Bajtín

Una de las preocupaciones de la crítica sobre el Lazarillo es considerarlo un texto satírico moralizador, vinculado al erasmismo. A nuestro juicio, tres razones básicas dejan al Lazarillo fuera de esa percepción: 1) no encontramos en él una actitud evaluadora, censuradora y aleccionadora con la que se procure enmendar los supuestos vicios y abusos representados; 2) Lázaro en lugar de burlarse sólo de los otros termina siendo también objeto de burla por parte de los demás y de sí mismo, y 3) la risa que se desprende del escarnio a que es sometido por sus amos y del autoescarnecimiento por contarnos su propia desventura es una risa festiva, jovial, generadora de deleite y amenidad en los lectores. El mundo cuestionado, evaluado y rebajado no es directa y exclusivamente el de los otros, sino también el del propio Lázaro que se autoescarnece al relatar su propio recorrido vital, social y moral. Más que ante un texto satírico estaríamos frente a un texto carnavalesco en el que se rompen las fronteras entre el burlador y el burlado y el mundo se vuelve al revés gracias al recurso de la parodia: la carta de Lázaro se enviste de la parodia para crear un mundo ambiguo y ambivalente que vuelve al revés el sistema de valores sociales, políticos, morales y espirituales establecidos mediante la entronización de lo bajo-material-corporal y el destronamiento de lo alto-sagrado-espiritual. Debido a estos dos procesos, el texto instaura una política somática que busca liberar al ser humano a partir de la satisfacción de necesidades primarias como la comida, la bebida y la sexualidad.

En este artículo queremos señalar las prácticas textuales, sociales y discursivas que vinculan al Lazarillo con la tradición popular de la risa. Para destacar dichas prácticas, discutiremos y cuestionaremos la pertinencia de las lecturas que lo visualizan como texto serio, doctrinario y moralizante al estilo erasmista; después destacaremos 
la función del caso dentro de la lógica de una autobiografía fingida, en la que sus elementos están al servicio del juego cómico y carnavalesco de la parodia. Finalmente, analizaremos la función social e ideológica del escarnio público del Lazarillo como práctica textual, social y discursiva en el marco de la una concepción carnavalesca.

Un vistazo a los estudios precedentes pone de manifiesto el carácter inestable que la crítica ha tenido frente al Lazarillo: fácilmente reconoce el sentido cómico-burlesco del texto, pero de inmediato lo emparienta con la sátira moralizante. Por un lado se dice que es una "mezcla de risa y de piedad, de hilaridad y de lástima" o que "El Lazarillo es un libro para hacer reír. un libro de burlas", pero a la vez se plantea que es una "obrita acerba, maliciosa, burlona y grave", que invita a reír, pero que "se propone la meditación y la ilustración, por medio de una mitología folklórica". La sátira se materializaría en su "áspero anticlericalismo" erasmista: el Lazarillo "es de un anticlericalismo desbocado. agresivo y total; se extiende a todo el clero sin excepción, ya sea regular o secular" ${ }^{3}$. Rico, además del carácter de divertimento del texto, deja entrever una segunda intención cuando plantea que el propósito del autor es "exhibir una muestra de espléndida artesanía humorística, al margen de toda implicación más o menos didáctica"4.

Esta tendencia a leer desde un ámbito académico ha convertido el Lazarillo en un texto serio, grave y con finalidad didáctico-moral, estableciendo con ello un dualismo cognoscitivo que contrapone ver$\mathrm{dad} / \mathrm{risa}$, seriedad / humor $^{5}$. Al ver todo a la luz de la gravedad, de lo

1. Manuel de Montoliu. Manual de literatura castellana (Barcelona: Editorial Cervantes, 1947) 391.

2. Marcel Bataillon, Noredad y fecundidad del Lazarillo de Tomnes (Salamanca: Anaya, 1968).

3. Maurice Molho, Introducción al pensamiento picaresco (Madrid: Anaya, 1972) 34 y 41.

4. Francisco Rico, La novela picaresca y el punto de vista (Barcelona: Seix Barral, 1989) 51-52. El destacado es mío.

5. Tómese en cuenta la "antipatía profunda por la novela picaresca" que siente Gregorio Marañón, dada "su profunda inmoralidad. su pesimismo, su sentido despectivo de lo español" (Gregorio Marañón, "Prefacio" a Lazarillo de Tormes, Buenos Aires: Espasa Calpe, 1964, p. 12). Marañón opone "alegría ruidosa. jocunda, de otros pueblos" derivada de la picaresca, a la "severa alegría ascética" de España. La única literatura del Siglo de Oro que merece su aprecio es la del honor, la de los místicos y la del romancero. 
elevado y de lo serio se descartan la risa y el humor como portadores de verdad. Romera Navarro planteaba que la novela picaresca, al ridiculizar los vicios sociales, ponía de manifiesto la necesidad de corregirlos. Pero - sostiene Romera- "creemos que tales novelas, con excepción acaso del Guzmán de Alfarache, no tuvieron otro objeto que distraer y regocijar a los lectores, siendo cosa de puro entretenimiento, sin tendencia alguna trascendental y moralizadora"6. Pese a este acertado juicio, que será nuestro punto de partida, el autor entronca la novela picaresca con una serie de textos que poseen finalidad didáctico-moral como el Libro de buen amor, El Corbacho, La Celestina, La lozana andaluza y Diálogo de Mercurio y Carón, sin llegar a plantear su ruptura o su novedad. De este modo, el carácter cómico del texto acaba envuelto y opacado por la finalidad didáctica que se le adjudica y pesa más dentro del balance general de la interpretación que se le hace al Lazarillo.

Por ahora no existe una visión de conjunto de la función de la risa en el Lazarillo y mucho menos un análisis de la exposición y de la autoexposición al escarnio que sufre Lázaro; tampoco se vincula el carácter burlesco del Lazarillo con la tradición popular de la risa carnavalesca de la Edad Media y del Renacimiento; pese a la insistencia de asociar el Lazarillo con una visión burlesca, cómica y deleitosa, los críticos no abandonan la idea de inscribirlo en el campo de la sátira moralizante; finalmente, la inscripción del texto en una finalidad satírica parte de una concepción de sátira en la que los cuestionados y necesitados de corregirse o enmendarse son los otros, los amos o el sistema de valores que ellos representan, razón por la que no se ve que el Lazarillo rompa con esa pretensión y coloca al propio protagonista en el centro de la mirada crítica y cuestionadora de los destinatarios.

6. M. Romera Navarro, Historia de la literatura española (Boston: Heath \& Company, 1949) 217 y 218. El destacado es mío. 


\section{Problemas con el carácter satírico del Lazarillo}

Discutamos primero la impertinencia de leer el Lazarillo dentro del circuito didáctico-moralizante y su vinculación con la sátira erasmista. Ambas preocupaciones adolecen, la primera de un sesgo ideológico que instrumentaliza la literatura a la enseñanza de valores y la segunda de una falta de análisis del texto fuera de la filiación autorial, razón por la cual se lleva a cabo una traslación mecánica de planteamientos desde la obra de Erasmo hasta las obras del supuesto autor y de ahí al Lazarillo. Dentro de esta óptica se ubica el reciente estudio de Navarro Durán, Alfonso de Valdés, autor del Lazarillo de Tormes (2003).

Sobre el carácter moralizador del Lazarillo, la crítica ha generalizado y trasladado mecánicamente la valoración del Guzmán como texto de tesis, doctrinario y moralizante hacia el texto inaugurador de la picaresca española. Al querer justificar que el Lazarillo también es un texto picaresco, los estudiosos han trasplantado la caracterización general establecida para la picaresca del siglo xVII hacia el texto anónimo del xVI, como si la producción de ese género fuera unitaria y hubiera surgido bajo las mismas motivaciones, circunstancias y propósitos. Tomemos como ejemplo dos de las características que se le atribuyen a la picaresca, son el carácter moralizante y el satírico. Sobre lo primero se indica:

Cada novela picaresca vendría a ser un gran ejemplo de conducta aberrante que, sistemáticamente, resulta castigada. La picaresca está muy influida por la retórica sacra de la época, basada en muchos casos, en la predicación de ejemplos, en los que se narra la conducta descarriada de un individuo que, finalmente, es castigado o se arrepiente.

Y sobre lo segundo se indica: 
La sátira es un elemento constante en el relato picaresco. El protagonista deambulará por las distintas capas sociales, a cuyo servicio se pondrá como criado, lo que le permitirá conocer los acontecimientos más íntimos de sus dueños. Todo ello será narrado por el pícaro con actitud crítica. Sus males son, al mismo tiempo, los males de una sociedad en la que impera la codicia y la avaricia, en perjuicio de los menesterosos que pertenecen a las capas más bajas de la sociedad ${ }^{7}$ (Menéndez, 1993).

Resulta evidente que esta caracterización es demasiado general y no se aplica a la novela fundacional del género: el Lazarillo no es portador de una conciencia pecaminosa, arrepentida y en procura de la gracia. Tampoco está saturado de ejemplos edificantes como el Guzmán, novela considerada prototípica del género, cuyas características se aplican a las demás sin partir de un análisis concreto de cada texto. En cuanto al carácter satírico, se supone que el estamento infiltrado por el pícaro es el eclesiástico, al cual se le develan sus males y sus vicios morales y espirituales. No se admite que el texto pueda apuntar hacia el mismo protagonista o que, en lugar de corregir a otros, esté corrigiéndose, complaciéndose y burlándose de sí. Según ese tipo de lectura, es contra los amos que arremete el Lazarillo: son ellos quienes deforman y corrompen la personalidad moral y espiritual del mozo:

Todos ellos [los amos] son censurables por sus vicios y responsables de la inversión de valores que sufre el pícaro... Lázaro confunde los valores morales con los materiales y cree que la honra se cifra en su estómago porque así le han enseñado sus maestros eclesiásticos, porque su vida ha sido una progresiva preparación para el deshonor. De este modo, quienes deberían

7. J. Menéndez Peláez y otros, Historia de la literatura española. Vol. II Renacimiento y Barroco (León: Everest, 1993) 113. 
haberle educado, los clérigos, incumplen su misión y son, paradójicamente, los principales causantes de su moral trastoca$d a$. La crítica contra la clerecía resulta, así, obvia ${ }^{8}$.

En ningún momento se visualiza la inversión de valores como una de las preocupaciones carnavalescas del texto. Se insiste en leer la novela como un documento que critica los desmanes de la clerecía pervertidora de la inocencia de un niño. Según esa lectura, el Lazarillo abogaría por el sistema de valores vigentes, razón por la que desenmascara la falta de valores de los clérigos que no cumplen con una misión formadora, sino más bien deformadora que trastoca los valores establecidos ${ }^{9}$. Se parte de un concepto efectista de sátira, según el cual el lector evaluaría, enjuiciaría y censuraría el estamento infiltrado por Lázaro. En lugar de ser el protagonista el indignado y encolerizado contra lo representado, es el lector, según sugiere Rey Hazas, quien debe irritarse contra los amos que han escarnecido vilmente al mozo inocente. La evaluación correctiva y negativa de este tipo de sátira provocaría en el lector un efecto denigrante y despreciativo hacia el mundo mostrado.

Esta lectura canónica no logra percibir la visión ambigua y ambivalente del mundo, la valoración del trastrocamiento y rebajamiento de los valores elevados y espirituales para entronizar y exaltar todo lo que tiene que ver con lo bajo material y corporal. La inversión de los valores que lleva a cabo el pícaro es censurada: "Lázaro confunde los valores morales con los materiales y cree que la honra se cifra en su estómago". Para nosotros, el Lazarillo encarna un constante proceso de entronización de lo material y corporal propio de la cultura popular de la risa carnavalesca, razón por la cual se pueden

8. Antonio Rey Hazas, La novela picaresca (Madrid: Anaya, 1990) 18. El destacado es mío.

9. Cfr. Antonio Vilanova, "Lázaro de Tormes como ejemplo de una educación corruptora". Actas del I Simposio de literatura española (Barcelona: Ediciones Universidad de Salamanca, 1981) 65-118; y Margarita Ferro, "Perversión del aprendizaje violento en el Tratado I del Lazarillo de Tormes". Espéculo 23 <www.ucm.es/info/especulo/numero23/lazarill.html> (consultado el 20 de diciembre del 2003). 
señalar varias razones que dificultan equiparar la carta con una función didáctico-moral:

1) El procedimiento paródico lleva a cabo una inversión de los valores, dada la fusión de lo serio con lo cómico, de lo elevado con lo bajo, de lo espiritual con lo material; 2) predomina una risa positiva, no destructiva, en la que el objeto no se encuentra sólo fuera, sino que lo constituye el mismo sujeto que se burla; 3 ) la novela no circula en un ámbito rígido y autoritario, con pretensiones correctivas, sino que se mueve en un ambiente amistoso, con el fin de agradar y deleitar; y 4) la fusión de lo cómico y lo serio crea una percepción ambigua y ambivalente, cuestión que impide tener una concepción fija, unívoca y monológica del mundo y de los valores que lo constituyen.

Según la supuesta vinculación del Lazarillo con la sátira erasmista, el texto estaría preocupado por develar la conducta anticristiana de los eclesiásticos: viciosos, ritualistas, exterioristas y contraejemplos de las virtudes evangélicas. La crítica ha querido ver en la escogencia de los amos de Lázaro una intención satírica al estilo erasmista, ya que cinco de ellos pertenecen al fuero eclesiástico. Además del escarnio contra los sacramentos de la eucaristía y del matrimonio, el ciego presentaría problemas religiosos como la caridad, la oración y el ejemplo ${ }^{10}$. La crítica ha reforzado este punto al señalar que el erasmista Alfonso de Valdés es el autor del Lazarillo. Rosa Navarro defiende que el texto guarda estrecha relación con Diálogo de Mercurio y Carón y con Diálogo de las cosas acaecidas

10. Son exponentes de esta tendencia M. Asensio, "La intención religiosa del Lazarillo de Tormes y Juan Valdés". Hispanic Review, XXVI (1959); J. L. Alborg, Historia de la literatura española, vol. I (Madrid: Gredos, 1966); J. Joset, "Lazarillo de Tormes témoin de son temps?". Revue des Langues Vivants, XXXIII (1967); F. Márquez Villanueva, Espiritualidad y literatura en el siglo XVI (Madrid: Alfaguara, 1968) y muchos otros que se repiten hasta la saciedad en manuales e historias de la literatura española. La versión más actual es la de Rosa Navarro Durán (2003). 
en Roma: los personajes tienen en común una vivencia de lo religioso condenable desde el erasmismo.

A nuestro juicio, no es posible homologar estas dos producciones textuales en cuanto a la finalidad didáctico-moral ni en cuanto a la filiación erasmista, primero, porque antes de Erasmo ya existía una tradición literaria, materializada en Las danzas de la muerte, que mostraba el mundo relajado de los clérigos ${ }^{11} \mathrm{y}$, segundo, porque las analogías que en los Diálogos sirven para relacionar y contraponer al mismo tiempo los sucesos relatados y los vicios a los que se corresponden nunca las vamos a encontrar en el Lazarillo: ninguna de las figuras de los amos y ninguna de sus prácticas y creencias encuentra su contraparte positiva en el texto anónimo. En lugar de separar y contraponer el vicio y la virtud, lo bajo y lo elevado, lo cómico y lo serio, el texto picaresco se complace en fusionar estos valores y en crear un mundo al revés. La parodia acentuará esta confluencia, a la vez que creará una concepción ambigua y ambivalente. Al no existir fronteras entre las prácticas externas y las creencias no se puede decir que el texto critique o satirice la religiosidad formularia, exterior y ritualista, objeto contra el que se levanta la sátira erasmista. Cualquier lección edificante y moralizante queda envuelta por la atmósfera cómicoburlesca en la que es sumergido el mundo superior, serio y ejemplar.

\section{El disimulo-fingimiento como eje estructurador de la carta}

Desde el punto de vista carnavalesco, la estructura del Lazarillo está sustentada por el procedimiento cómico del disimulo-fingimiento: lo central de la carta de Lázaro no es relatar el caso, sino fingir que lo cuenta ${ }^{12}$. Este juego es una estrategia de Lázaro para distraernos

11. Cfr. Kenneth Scholberg, Sátira e inventiva en la España medieval (Madrid: Gredos, 1971).

12. Aquí nos distanciamos de los aportes de Rico, quien defiende que el eje central sobre el que gira el texto es el caso como respuesta a la petición de Vuestra Merced ("Problemas del Lazarillo". Boletín de la Real Academia Española, XLVI, 1966; La novela picaresca y el punto de vista, Op. cit.), de Gómez ("La subversión del discurso ritual. Una lectura intertextual del Lazarillo de Tormes". Imprevué 1, 1980 y “Autobiografía y discurso ritual. Problemas con la confesión autobiográfica 
contándonos sus fortunas y adversidades. En principio, Lázaro simula que intenta hacer una confesión del caso, pero lo que nos of rece es lo hasta ahora vivido, cuestión que desplaza el caso. Dicha vida está precedida por un Prólogo serio-elevado que también sirve para velar lo bajo-cómico: la pretensión heroica del Prólogo es abortada cuando cuenta su genealogía bastarda y su vida rastrera en los Tratados: el Prólogo resulta ser una máscara épica que disfraza la comedia, su tono solemne sirve para ocultar el mundo antiheroico. Una vez ubicados en los Tratados, la carta de Lázaro nos coloca ante tres procesos de fingimiento con los que Lazarillo oculta lo que siente, lo que sospecha, lo que sabe y lo que hace: el primero realizado entre Lázaro y sus dos primeros amos: ambas partes fingen saber / no saber; el segundo realizado por sus amos ante los otros, mientras que Lázaro es un simple observador: los primeros disimulan el papel de saber / no saber, mientras que el criado devela al amo; y el tercero realizado por el mismo Lázaro ante Vuestra Merced y demás que leyeren su carta: aquí Lázaro sabe que sabe, pero dice no saber. El análisis de estos procesos pondrá de relieve el disfrazamiento del texto y su naturaleza cómica.

Veamos sólo los dos primeros casos. Las relaciones y las tensiones entre Lázaro y sus amos están mediadas y posibilitadas por el disimulo. Esta estrategia funciona como un pacto implícito que ayuda, en principio, a armonizar los conflictos, almacenar la descarga catártica y, después, termina convirtiéndose en la razón para ajustar cuentas. Lazarillo recurrirá a esta estrategia cada vez que se encuentre en una encrucijada o tema ser descubierto. El objetivo es burlar al otro para apropiarse de la comida o de la bebida, elementos negados, ocultados y custodiados por los amos. Los movimientos y las respueslas que da el criado a estos obstáculos ayudan a mantener la risa a flote

Il'ulinulu iI Irihunal inquisitorial". Imprevué 7, 1983) y de Cros, Ideosemas y morfogénesis del I'Vı I ViI virıl Virlap: Irankfurt am Main, 1992), quienes ven la respuesta de Lázaro como el

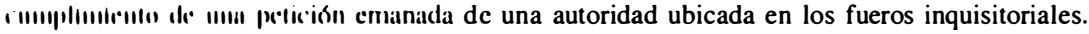

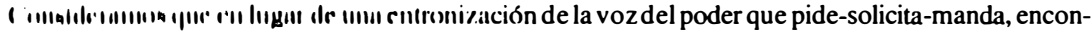

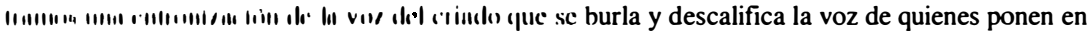

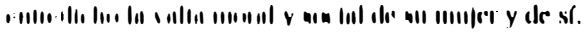


en el lector, ya que son engaños graciosos e inteligentes, como se presenta en el pasaje del jarro donde el ciego guarda el vino.

Dicho pasaje pone en juego dos fuerzas: una que lucha por apoderarse del vino y otra que busca evitar quedarse sin él. Lazarillo finge tener frío para tomarse el vino y el ciego descubre el ardid y calla como si nada supiera. Este doble fingimiento sirve para tejer la trama cómica del desenmascaramiento. El criado finge inocencia y el amo disimula ignorancia. La escenificación de la falta y del descubrimiento pone de relieve que ambos aspectos están revestidos de procesos calculados y tenidos en secreto por las partes, ninguna de las cuales sabe que el otro sabe y eso ayuda a crear la tensión cómica y a prepararse para el estallido cómico cuando la víctima se convierta en victimaria.

Lo mismo sucede en la escena del nabo y la longaniza: el mozo trueca la longaniza por el nabo (una cosa en lugar de otra, signo inequívoco del juego cómico) y deja al ciego asándolo mientras va por vino. Cuando regresa, ya el ciego ha caído en la cuenta del ardid. Para quedar libre del engaño, Lazarillo recurre a implicar a otro, pero este acto fingido no escapa a la astucia y clarividencia del amo, quien descubre, en las propias palabras del mozo, al culpable ${ }^{13}$. El recurso al otro en ausencia del mozo hace que aflore una serie de binomios antitéticos relacionados con la identidad: ausente / presente, estar / no estar, ser / no ser, yo / otro. Estas parejas remiten directamente al juego cómico de la confusión: escondido en sí mismo, Lazarillo se presenta como otro: al astuto se le antepone el ingenuo, al mañoso, el inocente, al victimario, la víctima.

En la escena del asalto al paraíso panal del Tratado II, el papel de fingidor o disimulador recae únicamente en el criado, quien se mimetiza en los supuestos ratones y en la supuesta culebra para mantener burlado al amo. La intención de engañar al clérigo está

13. El intento de ocultar-velar de Lazarillo se vuelve revelación-develación por parte del ciego, como en el relato que Lázaro hará del caso: lo que otros saben no se puede ocultar con las palabras del yo (el famoso "no sé qué y sí sé qué"). 
signada por varios elementos que ponen de relieve el plan premeditado del criado: esperar que el amo se duerma, levantarse quedito, haber dejado un cuchillo a la mano, perforar el arca para hacer creer que son ratones, ratonar el pan, cerrar y volver a sus pajas. Al día siguiente, ante la alarmante sorpresa del amo, Lazarillo se hace el maravillado. $\mathrm{Al}$ no creer que sean ratones, dado el carácter fantástico e inverosímil del suceso, los vecinos sugieren al clérigo la posibilidad de que sea una culebra. Esta idea llevará al clérigo a relacionar los sonidos escapados de la boca del Lazarillo dormido con los silbidos del reptil. Cuando el amo cree propinar una paliza a la culebra, quien la recibe es el criado. Este fingir ser y no ser ratón y culebra se convierte en un motivo cómico recordado y narrado con deleite por Lázaro. El paso del enmascaramiento hacia el desenmascaramiento pasa inevitablemente por la propina de una paliza, que se convierte en una especie de violencia cómica: "El ratón y [la] culebra que me daban guerra y me comían mi hacienda he hallado" 14 , son las palabras del amo que rubrican el sentido cómico-burlesco del desenmascaramiento.

Pero el fingimiento no es sólo una iniciativa de Lazarillo, sino también de sus amos, como lo ejemplifican el buldero y el alguacil. La actitud truculenta, artificiosa y mañosa del buldero queda expuesta.en las primeras palabras con que abre el Tratado V: "el más desenvuelto y desvergonzado y el mayor echador dellas que jamás yo vi ni ver espero, ni pienso que nadie vio" (p. 112. El destacado es mío). Esta hiperbolización de las mañas y destrezas del nuevo amo son equiparables a las del sabio, endemoniado y malvado ciego. Buldero y alguacil montan una escena circense para engañar al pueblo y lograr venderle las bulas. El templo será el espacio donde se lleve a cabo la escenificación del fingimiento y el fingido desenmascaramiento. Un fingimiento tan grande sólo puede tener como contrapartida un

14. Anónimo, Lazarillo de Tormes (Edición de Francisco Rico, 1987, 6ta. edición) (Madrid: Cátedra, 2002) 69. Todas las referencias serán tomadas de esta edición. De ahora en adelante las páginas se indicarán entre paréntesis después de la cita. 
develador extraordinario: Dios, quien "hará" un milagro para "desenmascarar" al falsario.

Esto es así para el público presente y para Lazarillo-testigo, no para Lázaro-autor ni para los lectores, quienes saben que el milagro es obra de la industriosa habilidad del buldero y de su cómplice. ¿Cómo llega Lazarillo a enterarse de la verdad, cómo llega a desenmascarar aquel tinglado de ardides, para que, como Lázaro, nos la pueda contar con deleite? La respuesta es muy simple: por medio de la risa:

Cuando él hizo el ensayo, confieso mi pecado, que también fui dello espantado y creí que ansí era, como otros muchos; mas con ver después la risa y burla que mi amo y el alguacil llevaban y hacían del negocio, conoscí cómo había sido industriado por el industrioso e inventivo de mi amo. Y, aunque mochacho, cayóme mucho en gracia, y dice entre mí: “¡Cuántas déstas deben hacer estos burladores entre la inocente gente!" (pp. 123-125. El destacado es mío).

Larisa se nos presenta como develador y principio gnoseológico en la experiencia de Lazarillo: no es un acto de seriedad ni de recogimiento interior lo que nos conduce a la verdad, sino un acto festivo y burlesco en el que los actores del fingimiento se gozan y se complacen: "la burla es la portadora de la terrible verdad" 15 con la que el inocente Lazarillo desenmascara el juego de su amo y el alguacil. Esta escena del buldero y del alguacil funciona como un texto en el texto: a la vez que pone de manifiesto la habilidad, el ingenio y la destreza con que opera el buldero para cautivar y persuadir a los feligreses, también resalta el carácter artificioso y fingido del programa narrativo para con sus parroquianos, cuestión que se equipara en todo con la hechura, ensambladura y estructura de la carta de Lázaro:

15. Salvador Aguado, Algunas observaciones sobre el Lazarillo de Tormes (Guatemala: Editorial Universitaria, 1965) 182. 
el estilo ceremonioso, litúrgico y elevado con que abre el buldero su apelación es similar al estilo elevado y grave con que Lázaro interpela tanto a su interlocutor privado como a la generalidad de sus lectores. Al final todos, al igual que los feligreses, somos embaucados por un narrador que nos hace consumir su carta como si fuera un verdadero testimonio de su vida y como si con este consumo fuéramos a lograr edificar nuestras almas. Pero las series de tramoyas, invenciones y artificios de que echa mano terminan develando la naturaleza mendaz y cómica de todo lo referido en la carta. El narrador también se ha vuelto industrioso y hábil para persuadirnos de las maravillas de su historia. La captación de ese sentido profundo sólo es posible gracias a la risa: descubrimos que todo lo planteado por Lázaro no es más que un juego, una ficción, gracias a las burlas y a las risas a las que nos expone y con las que reaccionamos ante el texto. El Lazarillo embaucado por el industrioso amo ha terminado industriado, esto es, enseñado y amaestrado, para hacer y decir con maña, destreza y habilidad lo atinente a su caso: como lectores terminamos consumiendo su vida sin ser satisfechos con lo prometido en el Prólogo.

\section{Hacia una lectura carnavalesca del Lazarillo}

Aunque muchos críticos han señalado que el Lazarillo no cumple con el propósito de la lectura útil y deleitable, ninguno ha llegado a proponer que ese contrafactum es ya una ruptura con su carácter satírico moralizador y el comienzo de una propuesta carnavalesca. Tanto el título como el Prólogo ubican el texto en un nivel elevado y modélico que lo equiparan a la literatura grave y patética, mucho más cuando se aproxima al precepto horaciano prodesse et delectare y se ampara en citas de reconocidos para fundamentarse y justificarse, cuestión que induce a pensar que estamos ante un texto moralizador. Esto tiende a reforzarse aún más cuando el Yo aparece como un Héroe épico del que se supone buena cuna y vida ejemplar. Esta imagen elevada es sólo la impresión que deja una primera lectura del Prólogo, 
porque conforme leemos los Tratados empieza a desdibujarse y a ubicarnos ante su aspecto paródico: lo grave, elevado y serio se convierte en cómico y burlesco al homologarse con las acciones, actitudes y peripecias por las que pasa el Yo y producen un efecto cómico en el lector. En tal sentido, estas primeras palabras se vuelven bivocales o de proyección paródica, ya que materializan lo serio y remiten al mismo tiempo a lo cómico. El texto, en lugar de ser una entronización de la virtud y del valor que caracterizarían al héroe, termina siendo la exaltación del deshonor y del vicio como contraparte del mundo edificado sobre supuestos valores morales y espirituales. El carácter modélico con que se enviste el Yo no sólo sirve para equiparar a Lázaro con la vida legendaria y mítica, sino que ayuda a instaurar un proceso de rebajamiento cómico una vez que nos enteramos de la clase de vida, del tipo de adversidades e infortunios por los que tuvo que atravesar: por pretender comida, bebida y mujer recibe golpes, palizas, humillaciones y es objeto de maledicencia.

Así, el Prólogo funciona como espacio de posicionamiento cómico del héroe en las posibilidades generales de lectura. Quien llega por primera vez al texto creerá que leerá la historia ejemplar de un héroe que ha sobrevivido a las adversidades de la vida con valentía, arrojo y virtud, luchando por alcanzar e instaurar valores elevados y sublimes. Una vez leídos los Tratados se descubre que el Prólogo es una máscara retórica sitiada de fuentes clásicas que apelan y convocan a la altura moral y al provecho del lector. Más que ante una retórica edificante, nos encontramos ante una retórica del divertimento: lo que emerge y permanece en el Prólogo es lo que se pretende ocultar (lo cómico) y lo que se pierde y esfuma es lo que se busca resaltar y explicitar (lo serio).

El Tratado I abre con la conversión paródica de la genealogía bastarda en genealogía heroica: el padre, molinero, ladrón y convicto es hecho bienaventurado y muerto en defensa de la religión; la madre amancebada se convierte en modelo para el hijo en su carrera de vivir, y el hijo renegado del padre se autoheroíza. El paso de una 
genealogía a otra está dado por la parodia: un hijo, autoheroizado con su nacimiento en el río como un Moisés o como un Amadís, no podía tener un padre de bajo rango, sino a un bienaventurado. Lo abominable de la procedencia de Lázaro es anulado por medio de la conversión paródica del origen humilde del héroe con padre perseguido y desterrado por causa de la justicia y muerto en combate defendiendo la religión. Tanto el hijo como el padre aparecen adscritos a una situación elevada, mientras que la madre queda sumida en una actividad baja y marginal, a la comida y al sexo, y no a aquellos supuestos valores elevados a los que se asocian padre e hijo. Pero, pese a no estar asociada a ninguna imagen trascendente, la madre quedará como el modelo a seguir por el hijo en su carrera de vivir: ella se amanceba y el hijo terminará amancebado. La conversión de esta genealogía infame en otra épica se constituye en una manifestación carnavalesca, en la que el juego social es posible gracias a la inversión de los valores establecidos y a la entronización de aquellos tenidos como censurables.

Al renegar del padre, Lázaro no sólo se convierte en un ser asocial, sino que también se coloca por debajo de las reglas y valores que rigen el mundo. Al preferir el sobrenombre, su carta se emparenta con la cultura popular de la risa. Sabemos con Bajtín que el nombre se relaciona con lo superior topológico, con lo serio y el respeto, remite a la epicidad, a la fama, a la glorificación y a la perpetuación de la vida en la memoria humana. El apodo, en cambio, tiende al polo de la injuria y de la maldición, es ambivalente y bipolar, surge en la frontera entre la memoria y el olvido, no perpetúa sino que refunde y regenera, se relaciona con lo inferior topológico y se inscribe en la espalda del hombre:

El nombre consagra, mientras que el apodo profana; el nombre es oficial, el apodo es familiar... En el apodo existe el momento de la negación, [de la] aniquilación [y de la] destrucción. No da bendición para iniciar la vida, no asocia a la eterna memoria, 
sino que despacha a la tumba corporal, para una refundición y un nuevo nacimiento, fungiendo como una especie de indicador de desgaste y defecto.... ${ }^{16}$.

Lázaro, desde el principio, quiere hacer patente su origen familiar sin avergonzarse de su procedencia descastada: al equiparar a su padre con elementos sagrados pone de relieve el carácter cómicoburlesco y contestatario de su confesión. Renunciar al nombre para asumir el sobrenombre sirve para cuestionar los privilegios de sangre de los nacidos en buena cuna, dado que la "fortuna fue con ellos parcial", mientras que Lázaro salió "a buen puerto [...] con fuerza y maña remando" (p. 11). Se invierte el mundo estamentalizado al descalificar a los que "heredaron nobles estados" y al exaltar a los que poseen un origen abominable. Rebajar a los que tienen buen nombre y entronizar a los que poseen apodo es ya un acto carnavalesco.

\section{La escenificación del escarnio}

El Lazarillo se ajusta más a un suplicio público cómico que a una subversión de la confesión inquisitorial, como suponen Gómez Moriana y Cros: la carta de Lázaro es la cuenta de las palizas recibidas de sus amos por procurarse comida y bebida. Este sufrimiento aparece teatralizado o escenificado: la víctima es escarmentada públicamente con la participación del amo-verdugo, la víctima expiatoria y una concurrencia de espectadores que presencia el acto vejatorio y humillante: Lazarillo es descubierto, prendido, delatadas sus travesuras y maldades a un público y castigado o afrentado por el amo. Este procedimiento tiene la estructura de un escarmiento públiço para corregir de palabra y de hecho al que ha errado y buscar su arrepentimiento. Pero dado el carácter carnavalesco que posee el texto, podemos señalar algunas modificaciones a ese castigo ejemplarizante:

16. Mijaíl Bajtín, "Adiciones y cambios a Rabelais" en S. Averintsev y otros, En torno a la cultura popular de la risa (Barcelona: Anthropos, 2000) 195-196. El destacado es mío. 
1. Estamos ante una sobriedad punitiva que minimiza la ferocidad del castigo y desemboca en una violencia cómica: el castigado, burlado y lloroso termina burlándose de su verdugo, de quienes se complacen en su dolor y de sí mismo. El dolor y el placer se mezclan, el sufrimiento y el deleite se fusionan: después del dolor y del llanto viene la risa, el rebajamiento cómico de aquello que rebaja física y sicológicamente. Esta risa le sirve a Lázaro para liberar su cuerpo golpeado y pasar de la tragedia a la comedia.

2. En ningún momento el narrador se detiene a meditar sobre lo sucedido para extraer de ello una enseñanza moral para sí o para los lectores de su caso. Dada su experiencia de burladorburlado-afrentado, se pone más de relieve la parte burlesca y cómica de sus desventuras que la parte seria y grave. El narrador, en lugar de ubicarnos del lado acusador de vicios y corrupciones, nos coloca en la parte humorística de su vida al plantearnos que si aquellas cosas no causan risa sería una gran injusticia.

Estas razones nos ubican ante una parodia del suplicio público y no ante un ritual de escarmiento: no estamos ante una víctima que se arrepienta y prometa enmendarse de sus errores, daños y perjuicios ocasionados a sus amos, a la sociedad, a las instituciones o al sistema de valores, sino ante una víctima gozosa y complacida en narrar su vida, que pone al revés el mundo y sus valores.

\section{El niño escarnecido por sus amos}

El paso de Lázaro por sus tres primeros amos sirve para escenificar cómo su desgracia, producto de la inocencia, es tomada como un espectáculo que produce o mueve a la risa, incluyendo al infortunado Lázaro. Su carta inscribe discursivamente el escarnecimiento en su propia vida y materializa el poder destructivo de una sociedad dispuesta a reírse del otro sin involucrarse en el ritual de la burla. 
Lázaro, en cambio, al reírse de sí mismo, desea escapar de los mecanismos de control social invocados por los amos. y la sociedad: al reírse de sí mismo, a la vez que descalifica, se distancia del poder de la risa destructiva que le viene de sus amos y del público espectador.

En el caso del ciego, el narrador-protagonista se complace en relatar las diversas situaciones en las que actúa como sisador y burlador del anciano. Los trompazos, pescozones, repelones y jarrazos sirven como preámbulo al caso del hurto de la longaniza por la que el ciego, furibundo, da una paliza a Lázaro. Al bullicio se acerca mucha gente que lo salva del amo. Éste aprovecha la concurrencia y comienza a contar las burlas del criado:

Contaba el mal ciego a todos cuantos allí se allegaban mis desastres, y dábales cuenta una y otra vez, así de la del jarro, como la del racimo, y agora de lo presente. Era la risa de todos tan grande, que toda la gente que por la calle pasaba entraba a ver la fiesta; mas con tanta gracia y donaire contaba el ciego mis hazañas, que, aunque yo estaba tan maltratado y llorando, me parecía que hacía sinjusticia en no se las reír (p. 41. El destacado es mío).

Este pasaje condensa lo que hemos llamado la escenificación del escarnio público ${ }^{17}$. Posee la morfología de una puesta en escena del ritual del castigo: el amo funciona como el verdugo, Lazarillo como la víctima y los presentes como los espectadores de esta ceremonia punitiva y festiva al mismo tiempo. La calle, como plaza pública, alimenta la concurrencia. La escena sirve para mostrar el juego cómico del burlador-burlado por el amo y por el público, pero también para sumar a ese juego el hecho de que el burlado se burle de sí y se incluya en el proceso del escamio. Esto nos coloca ante una

17. Jorge Ramírez Caro, La escenificación del escarnio en el Lazarillo. Hacia una lectura carnavalesca. Tesis de Maestría en Literatura Española (San José: Universidad de Costa Rica, 2004) 54-62. 
triple escenificación del burlador: el burlador activo, el burlador pasivo y el burlador agente: Lázaro se burla de las argucias y estrategias de su experimentado amo; Lázaro es burlado por su amo y por el público espectador y Lázaro termina siendo un burlador de la burla del ciego y del público y un burlador de sí mismo.

Los amos de Lazarillo podrán decir que todo burlador termina burlado, pero Lázaro agrega una nueva perspectiva que lo emparenta con la cultura popular de la risa y lo aleja del carácter satírico: todo burlador burlado puede burlarse de la burla, de sus burladores y de sí mismo. Esto nos ubica ante un triple proceso carnavalesco: uno de entronización (un burlador que se burla de alguien más experto), otro de rebajamiento (un burlador que es burlado por su amo y por el público) y un tercero de reentronizamiento (un burlador burlado que se atreve a burlarse de esa burla y de sí mismo). Estos procesos en lugar de rebajar y humillar a la víctima la reavivan y la llevan a convertir el desprecio de los demás en el atractivo para sí al ofrecer su caso como una maravilla divertida.

Esta escena también es otra especie de texto en el texto. El ciego, narrador de los desmanes de Lazarillo, se equipara con el Lázaro narrador: ambos convocan a un público para contarle las fortunas y adversidades del criado y esa narración busca agradar y divertir a los congregados. El Lazarillo no es más que la actualización ampliada de ese núcleo narrativo instaurado por el ciego y llevado hasta las últimas consecuencias al implicar y complicar su recorrido vital. El mismo Lázaro, que reconoce la gracia y el donaire del ciego, capaz de producir risa tanto en el público presente como en el mismo objeto de escarnio, también solicita que reconozcamos la gracia presente en su carta. Este reírse de sí mismo resucita o revive a la víctima de los golpes y descalabros propinados por el ciego.

\section{El Lazarillo y las series carnavalescas}

La insistencia en la comida, en la bebida, en la sexualidad y en la violencia física en el Lazarillo nos remite a lo que Bajtín llama las 
series carnavalescas ${ }^{18}$. Retomo algunos segmentos mencionados para darle coherencia a este asunto. En el Lazarillo encontraremos las series del cuerpo, la de la comida, la de la bebida, la de la sexualidad y la de la muerte. Estas series se imbrican y se relacionan unas con otras, de modo que difícilmente se pueden ver separadas. La única escena que se puede ver de modo independiente es la relacionada con la calabazada iniciática con que el ciego estrena a su criado. Recordemos la escena: el ciego pide que Lazarillo se acerque al toro de piedra para que oiga el ruido; cuando el criado apoya la cabeza, el ciego se la estrella contra la mole:

- Necio, aprende, que el mozo del ciego un punto ha de saber más que el diablo.

Y rió mucho la burla.

Parecióme que en aquel instante desperté de la simpleza, en que, como niño, dormido estaba... (p. 23. Los destacados son míos).

La escena no sólo sirve para introducir la pareja cómica ciegocriado, propia de la literatura folclórica de la que se alimenta el carnaval, sino también para ubicarnos frente a los juegos del bobo como víctima del listo. Las series antitéticas así lo sugieren: por un lado, Lazarillo-niño-simple-ingenuo y, por el otro, ciego-viejo-astuto-malicioso. Esta situación cambia después del golpe y de la burla de la que es objeto el criado, quien "despierta de la simpleza". Se conjuntan violencia y burla como elementos propios del juego cómico: la violencia sirve para que aflore el conocimiento o la sabiduría en los simples. Esto sugiere la relación saber-dolor, a la vez que separa el saber de lo divino y lo vincula con lo demoníaco.

Esta ceremonia iniciática tiene su cierre invertido en la calabazada del ciego contra el, ya no toro, sino poste de piedra: ahí demuestra

18. Bajtín describe las siguientes series: la del cuerpo humano en su aspecto anatómico y fisiológico, la de la comida, la de la bebida y la borrachera, las sexuales, la de la muerte y la de los excrementos. Teoría y estética de la novela (1975) (Madrid: Taurus, 1989) 321-328. 
Lazarillo no ser un necio ni un simple, sino un astuto y perverso como el Demonio. El antes simple e ingenuo Lazarillo ahora es astuto y malicioso, y el astuto y malicioso ciego aparece ahora como un simple e ingenuo. Mientras el ciego triunfa en los cuatro primeros casos (toro de piedra, uvas, vino y longaniza), después de una escalada de tretas y de contratetas, pierde su última partida ante un mozo que ha llegado a superarlo en esta serie de duelos por la sabiduría y el poder. Así, la victoria de Lazarillo sobre el ciego se puede ver como una "victoria sobre el diablo"19.

Veamos la serie de la bebida y su entrecruce con las series de la comida, la del cuerpo flagelado, la de la sexualidad y la de la muerte. Lazarillo se las ingenia de múltiples formas para beberse el vino del ciego. Recordemos el pasaje de la significativa y simbólica disputa del vino: Lazarillo se muere por el vino, el ciego oculta el jarro entre las piernas, el criado finge tener frío y se le cuela hasta el bajo vientre, el ciego cae en la cuenta, le descarga un jarrazo en la cara y le quiebra un diente, después lava con vino al mozo herido y rubrica con estas palabras: “¿Qué te parece, Lázaro? Lo que te enfermó te sana y da salud" (p. 33. El destacado es mío). Uno se pregunta por qué tan ardiente deseo por el vino en el criado y tanto celo por custodiarlo en el amo: como el vino es símbolo del conocimiento y de la iniciación, uno quiere ser sabio y el otro no desea ser simple. Está en juego la demostración de la autoridad y de la superioridad del saber.

Anterior a la escena, el criado ha utilizado "una paja larga metiéndola en la boca del jarro, chupando el vino". Estos elementos son equiparables con los de la escena de la longaniza cuando el ciego "abríame la boca... metíame la nariz, la cual él tenía luenga y afilada" (p. 40). Estos ingredientes constituyen una escena altamente erótica que afirma lo bajo corporal: el ciego "asentaba su jarro entre las piernas" y el criado "fingendo haber frío, entrábame entre las piernas del triste ciego a calentarme". Dado que la visión carnavalesca insiste en

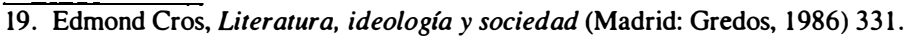


orificios como la boca abierta, los genitales, los senos, las barrigas y la nariz ${ }^{20}$, el verbo entrar utilizado por Lázaro supone una referencia a las partes abiertas del cuerpo, dispuestas a recibir y que aproximan al ciego con la boca abierta del jarro.

La relación criado-pajilla larga lo hace portador de lo masculino y la relación ciego-jarro, portador de lo femenino. De este modo se sugiere la cópula por medio de la penetración de la "pajilla larga" de Lazarillo en la "boca del jarro" del ciego, relación erótica que se invierte en la escena de la longaniza: la "nariz larga" del ciego es la que penetra en la "boca abierta" de Lazarillo. Completa esta atmósfera erótica una serie de marcas sugestivas y sensoriales como comer, beber, chupar, saborear, lamer. Como resultado final tenemos el intercambio de los papeles femenino y masculino, la eliminación de las fronteras y de las dualidades: el mundo se integra en una completa unidad, los contrarios se fusionan en esta visión carnavalesca.

Por otro lado, el contacto de Lazarillo con el vientre del ciego, otra especie de fusión de los cuerpos, sugiere la imagen carnavalesca de la vejez embarazada, lo cual remite a la serie del nacimiento y la muerte, tal como lo ha propuesto Bajtín. En el vientre del ciego, Lazarillo busca calor, protección, abrigo, pero también vino, alegría, vida. Este anciano embarazado arrojará, violentamente, a su hijo. El criado estaría asociado a la infancia y a la vida, mientras que el amo lo estaría a la vejez y a la muerte. Se refuerza así la inversión de lo masculino-femenino destacada anteriormente por medio de la expresión "siendo ciego me alumbró", en la que alumbrar no sólo remite a iluminar, sino también a generar, crear, parir: "después de Dios, éste me dio vida" (p. 24). De este modo, el ciego se convertiría en la madre-padre del Lazarillo: "me recibió, no por mozo, sino por hijo" (p. 22). La muerte ha dado luz a la vida, la vejez a la juventud y la

20. Mijail Bajtín, La cultura popular en la Edad Media y en el Renacimiento (1987) (Madrid: Alianza Editorial, 1990) 30. 
enfermedad a la salud, como sugieren las palabras del ciego: "Lo que te enfermó te sana y da salud" (p. 33) ${ }^{21}$.

Todas estas series afirman una materialidad necesitada e insatisfecha. El cuerpo se convierte en la unidad donde convergen los valores que rigen la vida del mozo. Lo considerado como perecedero y pecaminoso, grosero y sucio en la concepción medieval monológica es para Lázaro la piedra fundamental sobre la cual edifica su nuevo estatuto social, moral y espiritual. Aquella vida corporal negada y carente de sentido aparece afirmada y dotada de un significado profundo desde el punto de vista antropológico y ético: sólo se puede vivir si se tienen satisfechas las necesidades primarias. Con este planteamiento Lázaro contesta y desenmascara la ideología sobre el cuerpo en la que se envuelve el mundo de los clérigos:

Mira, mozo, los sacerdotes han de ser muy templados en su comer y beber, y por esto yo no me desmando como otros. Mas el lacerado mentía falsamente, porque en cofradías y mortuorios que rezamos, a costa ajena comía como lobo y bebía más que un saludador (p. 52. Los destacados son míos).

\section{La supuesta mesura y frugalidad con que los clérigos deberían} tratar el cuerpo se asocia con el poco valor que se le concede a lo

21. La serie del cuerpo ba jo el aspecto anatómico se lleva a cabo mediante la descripción de los daños, rajaduras, heridas, quebraduras que recibe el criado de mano de sus amos en la cara, en la boca, en los dientes, en la cabeza, en el estómago: Lazarillo es la imagen del descalabrado. La serie de la comida es la más predominante y se entrecruza con la del cuerpo: Lazarillo es molido a palos por procurarse el alimento, al igual que Zaide, quien no sólo recibe azotes, sino además pringues de aceite hirviente. La serie sexual no sólo se da en casos como en el Tratado IV, sino también mediante el aspecto de analogía fantástica y grotesca cuando el ciego introduce su larga nariz por la boca hasta el estómago del criado, y en la perforación y penetración de las manos, de la llave y de la culebra en el arca. La serie de la muerte se presenta en un Lazarillo que se muere por no comer: "A cabo de tres semanas que estuve con él [clérigo] vine a tanta flaqueza, que no me podía tener en las piemas de pura hambre. Vime claramente ir a la sepultura" (p. 51). Puede ampliarse la relación cuerpo-hambre-muerte con el pasaje de los mortuorios: Lazarillo ruega a Dios para que hayan muertos todos los días y así comer y tener vida: "si el día que enterrábamos yo vivía, los días que no había muerto, por quedar bien vezado de la hartura, tornando a mi cotidiana hambre, más lo sentía. De manera que en nada hallaba descanso, salvo en la muerte, que yo también para mí, como para los otros deseaba algunas veces; mas no la vía, aunque estaba siempre en mî” (p. 53). 
material-corporal tenido, no sólo como perecedero, sino también como espacio donde se asienta el Demonio. Al negativizar el cuerpo y la satisfacción de las necesidades de lo bajo corporal se busca eliminar la relación con el mundo por medio de lo material, para mantener intacta y pura la relación con lo superior y elevado por medio del espíritu o del alma. Lázaro desenmascara la ambigüedad ideológica de esta concepción medieval: mientras concibe al cuerpo bajo el signo de lo perecedero y de la superación, en la práctica reina un desenfreno corporal-material. El clérigo, en lugar de explicar el comportamiento corporal de la vida, termina negándolo, dándose una separación desmesurada entre la palabra y el cuerpo. En cambio, Lázaro no sólo pone de manifiesto su contraposición a esa concepción disfrazada, sino que revela el nuevo modo de ver la imbricación entre la vida, la corporeidad, el mundo y los valores. En este sentido, las series carnavalescas en el Lazarillo vienen a destruir la vieja imagen del mundo y a construir una nueva imagen, en cuyo centro reside un hambre total, tanto física como espiritual. En el mundo de sus amos, Lázaro no desea contemplar el pan ni adorar el vino al estilo místico-ascético, sino mantener contacto directo con ellos, convertirlos en alimento. Alejarlo de ellos sería el fin, el anuncio de la muerte, la caída de todas sus expectativas. 